\title{
Living with an ileostomy: a case study on the transition process
}

Viver com uma ileostomia: um estudo de caso sobre o processo de transição Vivir con una ileostomía: un estudio de caso sobre el proceso de transición

Carla Regina Rodrigues da Silva*; Florbela Sousa**; Jorge Luís Machado Vale Lima***; Maria do Carmo Pinto****; Maria Alice Correia de Brito*****; Inês Maria da Cruz ${ }^{* * * * * *}$

\section{Abstract}

Background: An ileostomy affects the person's identity, leading to a process of transition. The person's response to transition, as the subject of nursing study, should be explored, as well as the context in which the transition is experienced.

Objective: To describe and understand the transition phenomenon experienced by a person with an ileostomy and diagnosed with familial adenomatous polyposis, based on Afaf Meleis' Transition Model.

Methodology: An instrumental case study was conducted using the qualitative research paradigm. The case was selected through a convenience sampling strategy and data were collected through observation, analysis of the electronic nursing records, and semi-structured interviews.

Results: The person and the context involved in the transition process are two non-recurring realities that influence its course.

Conclusion: Afaf Meleis' Transition Model allows understanding the transition process experienced by the ileostomy patient in terms of nature, conditions, and response patterns of transitions.

Keywords: nursing theory; ostomy; ileostomy

\section{Resumo}

Enquadramento: A confeção de uma ileostomia constitui um evento capaz de afetar a identidade da pessoa, levando-a a experimentar um processo de transição. As respostas humanas envolvidas nas transiçóes, como objeto de estudo da enfermagem, necessitam de ser exploradas, na pessoa e no contexto de quem as vive.

Objetivos: Descrever e compreender o fenómeno de transiçáo vivido por uma pessoa com ileostomia com polipose adenomatosa familiar, a partir do modelo de transição de Afaf Meleis.

Metodologia: Estudo de caso único, do tipo instrumental, conduzido sob o paradigma de investigação qualitativo. $\mathrm{O}$ caso foi selecionado por conveniência e a informação recolhida através da observação, da análise aos registos eletrónicos de enfermagem e de uma entrevista semiestruturada. Resultados: A pessoa e o contexto envolvidos numa transição são duas realidades que não se repetem e que influenciam o curso do processo de transiçáo.

Conclusáo: $\mathrm{O}$ modelo de transiçấo de Afaf Meleis permite compreender o processo de transiçáo vivido pela pessoa com ileostomia quanto à natureza, condiçóes e padrōes de resposta envolvidos.

Palavras-chave: teoria de enfermagem; ostomia; ileostomia

*MSc, Nurse Specialist in Medical-Surgical Nursing Nursing School of Porto, $4200-072$ Porto, Portugal [enf carlasilva@hotmail.com]. Contribution to the article: literature sePorto, Portugal [enf_carlasilva@ hotmail.com. Contribution to the article: literature search, case selection, data collection, treatment, analysis and discussion, article writing 4200-072, Porto, Portugal.

4200-072, Porto, Portugal. Porto FG, EPE $4460-762$ Custóiss, Porto [roming, Portuguese Institute of Oncology -

the article: literature search, data analysis and discussion, overall article revision.
$* * *$ MSc., Nurse Specialist in Medical-Surgical Nursing, Healthcare Center Soares dos ***MSc., Nurse Specialist in Medical-Surgical Nursing, Healthcare Center Soares dos
Reis, 4400-043, Vila Nova de Gaia, Portugal [jorge valelima@gmail.com]. Contribution Reis, 4400-043, Vila Nova de Gaia, Portugal [jorge.valelima@gmail.com]. Contribution
to the article: literature search, data analysis and discussion, overall article revision to the article: literature search, data analysis and discussion, overall article revision.
$* * * *$ MSc., Nurse Specialist in Medical-Surgical Nursing, Portuguese Institute of Onco*
logy - Porto FG, EPE, 4200-072, Porto, Portugal [mariadocarmo.pinto $@$ gmail.com] Contribution to the article: literature search, data analysis and discussion, overall article revision.

revision. ce@esenf.pt]. Contribution to the article: data analysis and discussion, overall article revision.

******MSc., Adjunct Professor, Nursing School of Porto, 4200-072, Porto, Portugal [inescruz@esenf.pt|.Contribution to the article: data analysis and discussion, overall article revision.

\section{Resumen}

Marco contextual: Una ileostomía puede afectar a la identidad de la persona y llevarla a experimentar un proceso de transición. Es necesario explorar las respuestas humanas involucradas en las transiciones, como objeto de estudio de la enfermería, en la persona y en el contexto de quienes las viven.

Objetivos: Describir y comprender el fenómeno de transición vivido por una persona con ileostomía con poliposis adenomatosa familiar, a partir del modelo de transición de Afaf Meleis.

Metodología: Estudio de caso único, de tipo instrumental, conducido de acuerdo con el paradigma de investigación cualitativo. El caso se seleccionó por conveniencia y la información se recogió a través de la observación, el análisis a los registros electrónicos de enfermería y una entrevista semiestructurada.

Resultados: La persona y el contexto involucrados en una transición son dos realidades que no se repiten y que influyen en el transcurso del proceso de transición.

Conclusión: El modelo de transición de Afaf Meleis permite comprender el proceso de transición vivido por la persona con ileostomía en cuanto a la naturaleza, las condiciones y los patrones de respuesta involucrados.

Palabras clave: teoría de enfermería; ostomía; ileostomía

Received for publication: 06.03 .17

Accepted for publication: 17.05 .17

Série IV - n. ${ }^{\circ} 14$ - JUL./AGO./SET. 2017 


\section{Introduction}

Ostomy and stoma are terms used to describe an exteriorization of any hollow viscera through the body. Stomas are defined differently depending on the area of the body from which they originate (Santos, 2015). An ileostomy is, thus, an intestinal derivation in the small intestine, in which the ileum is exteriorized through the abdominal wall to pass stool and gas (Burch, 2015).

The person with a stoma (e.g., ileostomy) goes through a transition process. The transition experience is triggered by critical events and changes in the person or the environment and begins as soon as the event or the change takes place, and it is characterized by a period of instability (Meleis, 2010). The transition to a life with an ileostomy brings about multiple, meaningful, and long-lasting changes. Some of the changes that compromise patients' physical and emotional functioning include body changes, dissatisfaction with physical appearance, incontinence, odor, gases, adjustments in diet and clothing, difficulties while traveling, and complications associated with the stoma and devices (Brown $\&$ Randle, 2005). These changes are likely to cause psychosocial problems in people living with a stoma such as: anxiety; depression; feelings of loneliness; lack of control; tiredness and stigma; decreased self-esteem and social activities; job loss; and, even, sexual disorders (Vonk-Klaassen, de Vocht, den Ouden, Eddes, \& Schuurmans, 2016).

In this way, specialized nursing care should promote autonomy in stoma self-care and quality of life for patients, families, and/or caregivers (Registered Nurses' Association of Ontario [RNAO], 2009).

Therefore, the concept of transition is central to the nursing discipline. Among health professionals, nurses are often the first point of contact for patients and families undergoing transition process(es) (Youn-Jung \& Mi-Ae, 2015). In this context, the relevance of this study is justified by the fact that nurses should understand the transition process from the perspective of those who experience it. Nurses play a key role in data collection, which enables them to recognize the meaning of the transition. Upon the identification of a state of vulnerability that may lead to unadjusted transition processes, nurses should guide the person toward a successful/healthy transition. Thus, this study aims to describe and understand the phenomenon of transition experienced by a ileostomy patient diagnosed with familial adenomatous polyposis (FAP), based on Afaf Meleis' transition model.

\section{Background}

The transition process becomes a nursing focus area when it interferes with health or when the response to transition is mediated by health-related behaviors (Meleis, 2010). Some changes that occur throughout the lifecycle, whether desired or imposed, may interfere with the person's health status and, therefore, may lead to a transition (Kralik, Visentin, \& van Loon, 2006).

Meleis, Sawyer, Im, Hilfinger Messias, and Schumacher (2000) argue that the transitions theory can provide guidance for nursing care delivery to people experiencing different types of transitions since it provides a comprehensive perspective on the nature, type, conditions, and patterns of response of transitions. However, these authors argue that the transitions theory must be further developed through theoretical studies and that its applicability must be reassessed in research and clinical practice.

Therefore, the transitions theory must be applied, as a middle-range theory, to concrete transition experiences. On the one hand, this will allow checking the scope and applicability of the theory and, on the other hand, contribute to the development of the theory itself.

The transitions theory includes four core concepts: the nature of the transitions, the transition conditions, the patterns of response, and the nursing interventions.

With regard to its nature, transitions can be analyzed according to their type, pattern, and properties.

Transitions depend on the situation that triggers them, which is always characterized by a change. Transitions can be classified as follows: health/illness transition, developmental transition, situational transition or organizational transition (Meleis, 2015). 
Health/illness transitions, which will be explored in this study, arise from a change in the health condition, a change from a healthy state to a state of disease or worsening of the health condition. This type of change requires new behaviors, resources, and strategies to cope with the rupture, alteration or restoration of relations during this process (Meleis, 2015). The person who is diagnosed with FAP and needs to undergo an ileostomy faces many unknowns, uncertainties about the future, and fears about the consequences of this process (Meleis, 2015).

The properties of transition are time span, process, disconnectedness, awareness, and critical points (Meleis, 2015).

Transition has a beginning and an end; it begins when the person is aware of the change and ends fluidly when the person assumes the new roles, develops the necessary skills, and achieves a feeling of well-being or the desired quality of life (Meleis, 2015).

Transition is a process. The event or situation that makes the person aware of change is, in itself, static, but the experience of transition is characterized by a dynamic and fluid process (Meleis, 2015). The same person may experience more than one transition simultaneously. Transitions can be single or multiple, sequential or simultaneous, related or unrelated (e.g., a person experiencing a health/ illness transition due to a FAP diagnosis and an ileostomy while experiencing a situational transition related to the previous transition as a result of the change in the tasks performed at the workplace due to the ileostomy).

Disconnectedness is another property of transition that is associated with the feeling of disruption with what was previously known, familiar, and comfortable. The person experiences a feeling of loss and a sense of discrepancy between past, present, and future expectations, feeling disconnected from reality because the patterns of normalcy in their everyday life are interrupted by unknown changes (Meleis, 2015).

Another important property of transition is awareness. In most cases, transition requires an awareness of change, the situation that triggered the transition, and the inner experience of transition. The difference between change and transition is that change is an ex- ternal experience and transition is an internal experience. Transitions are both a result of and result in changes (Meleis, 2015). When the person is not aware, it is important to first overcome the barriers that limit the sensitivity to awareness before attempting to facilitate transition itself. Nurses play a key role in these situations (Meleis, 2010).

The existence of markers of transition as turning points in the transition process is also a property of transition.

Some transitions are associated with events such as the diagnosis of a disease (e.g., FAP), while others occur without easily identified events associated with it. These critical points are characterized by instability, uncertainty, and disruption with reality and can facilitate or inhibit the transition process (e.g., wrongly changing an ileostomy bag can be a negative critical event). The identification of critical events is essential to understand the stages and the direction of the transition experience, as well as to identify appropriate moments for assessment and intervention. According to Meleis (2015), the goals of transitions theory are to describe events/situations (mental triggers) that trigger the transition process, anticipate the transition experience, predict outcomes, and provide guidelines for nursing interventions.

In order to understand the experience of transition, it is also necessary to take into account the transition conditions, which are associated with both internal and external constraints in patients' lives.

Personal conditions include the meanings and values assigned to the change and the context of change. Individuals' responses during the transition experience also depend on their level of Knowledge about change and ability to change, as well as their beliefs about what is expected from a person experiencing changes. The level of planning, health, and well-being of the person, family, organization, community, and country itself are also personal conditions that could interfere with the transition experience. Meleis (2015) adds that the individual's responses are mediated by the person's level of vulnerability versus sense of marginalization during the transition process.

As in the personal conditions, the conditions 
of the community/society and the global conditions can interfere with the transition process (Meleis, 2015). For example, in a stereotypical society, a person with an ileostomy will feel stigmatized, which will affect his/her transition process.

Studies have shown that there are response patterns in the transition process. These patterns can be monitored by process and outcome indicators that provide relevant data on the evolution of the transition.

Process indicators allow assessing how the transition process is unfolding. They include the degree of engagement, feeling located/ situated, seeking and receiving support, and level of confidence (Meleis, 2015).

On the other hand, outcome indicators allow identifying the end of the transition. Transition is completed when the individual masters his/her new role and integrates feelings, goals, and behaviors in his/her identity with confidence, knowledge, and expertise. The person begins to accept the new identity in a fluid manner, demonstrating proficiency in the management of his/her new condition and the ability to develop healthy interactions and connections (Meleis, 2015).

Understanding the nature of the transition, its conditions, effects, and response patterns allows nurses to intentionally implement interventions aimed at caring for the person who experiences a transition. Nursing interventions aim at promoting healthy process and outcome indicators in the person who experiences a transition (Meleis, 2015). Therefore, according to Meleis (2015), nurses are expected to prescribe interventions that clarify meanings, develop competencies (knowledge, skills, and attitudes), set goals, model the role of others, provide resources and opportunities for training/development, as well as facilitate the access to reference groups and role models that allow sharing experiences around critical events.

FAP is a syndrome characterized by the presence of hundreds of thousands of polyps in the epithelium of the large intestine due to an autosomal dominant inheritance. Most people who are diagnosed with FAP have a family history of polyps and colorectal cancer, although 25 to $30 \%$ of them have no clinical or genetic evidence of FAP in family mem- bers. The therapeutic option of choice is prophylactic proctocolectomy since all patients diagnosed with FAP will eventually develop colorectal cancer (Dalavi, Vedpalsingh, Bankar, Ahmed, \& Bhosale, 2015).

The changes resulting from the FAP diagnosis and those associated with an ileostomy cause the person to experience a transition process toward the adaptation to the new condition, which translates into the mastery of ileostomy self-care and the fluid integration of the new identity, until the difference is no longer a difference. The transitions theory can, therefore, contribute to understanding this transition that often occurs in nurses' clinical practice.

\section{Research question}

Is the transitions theory useful to understand the transition process experienced by the ileostomy patient?

\section{Methodology}

Taking into account the objective of the study, a case study was conducted since this is an appropriate methodological research approach to explore, describe, and understand complex events and contexts in which several factors and constraints are simultaneously involved. Although the case study focuses on the circumstances, the dynamics, and complexity of a single case or a small number of cases (Bowling, 2014), it is preferable to explore, in depth and over time, a single unit (one individual) as an isolated case study.

Given the conceptual framework under analysis and the fact that the purpose is to describe and understand the transition process experienced by a ileostomy patient diagnosed with FAP based on this framework, a case study was conducted under the paradigm of qualitative research.

With regard to the type of case study, and according to Stake's classical reference (Stake, 1995), it can be classified as an instrumental case study, to the extent that the case is explored to provide an introspection about a topic, refine a theory, or provide knowledge 
about something other than just the case itself. The case study serves as a tool to understand the transition process experienced by an ileostomy patient diagnosed with FAP, as well as to assess the scope and applicability of the transitions theory in nursing clinical practice. Since the goal of a case study is not used to understand other cases but rather the single case under analysis, the sample must always be intentional. In this study, an intentional convenience sampling method was used to select the case study.

As a way of ensuring the accuracy of the results obtained, data triangulation was used (Bowling, 2014), since triangulation allows obtaining data on the same event from two or more sources of information, thus increasing data reliability. To collect case-related data, different sources of information were used, namely structured observation, electronic nursing records, and semi-structured interviews. Data were collected during 10 days of contact with the case (the period of 10 days immediately after surgery).

Each case is unique, although there may be some aspects similar to other cases. However, the issue of external validity is not relevant for this study since the generalization of results is not consistent with its purpose.

Since the case and the context, as single entities, cannot be replicated or rebuilt, it is not possible to consider that data collected in this study remain stable over time. The transition process experienced by the case is conditioned by the time factor.

This study met the ethical principles for health research involving human beings. Data collection was authorized by the ethics committee of the health institution involved in the research study with the identification code 30.MAI11 09526. The participant gave his informed consent to participate in the study. Data confidentiality was ensured.

\section{Results}

The case under analysis was a male adult aged 27 years, single, and living with his mother and four siblings. He had the $7^{\text {th }}$ grade and worked in a timber company as a machine operator. His father died when he was 6 years old from colorectal cancer without ever giving consent to a colonoscopy or any surgical intervention. In his father's family, two cousins had also died from colorectal cancer and three other cousins were submitted to a temporary ileostomy, which had already been closed at the time of the study. The patient himself had no relevant history of disease, but he had a family history of colon polyps and colorectal cancer. A colonoscopy was performed, as well as a genetic study that confirmed the mutation of the APC gene and the FAP diagnosis. As a therapeutic modality, the following procedure was suggested: ileoproctostomy with J-pouch and ileostomy.

Stoma-forming surgery was a new situation for the patient, although not completely unknown or unexpected given his direct family history. Despite this, the patient reported never having seen an ileostomy bag and it was clear that he had never seen an ileostomy when he mentioned that: "I knew that my cousins had a bag, but I never saw it!" (I1; 13 June, 2011).

The patient's perspective about the change showed his belief in the reversibility of the elimination function as he believed that, like his cousins, the ileostomy would be later closed: "I just want to be OK, healed. Then I'll remove the bag, just like my cousins" (I1; 13 June, 2011).

Although he had never seen "his cousins' bags" (I1; 13 June, 2011), the relationship of proximity between them allowed the patient to become familiar with the limitations that he had identified in his cousins' lives: "I remember that when my cousins had the bag ... they couldn't do everything they wanted, they had to be careful!".

In this context, the patient showed interest in improving his knowledge about the disease and its impact, as well as in developing his ileostomy self-care skills: "I want to know more about my disease and the bag" and "I want to learn how to care for the bag" (I1; 14 June, 2011).

Although he had never seen an ileostomy, the patient felt no aversion when seeing it for the first time. At this moment, he asked several questions and interacted with the nurse to obtain information, and with the mother and sister for positive reinforcement. 
Throughout the process of developing ileostomy self-care skills, the patient was pleased with his mother and sister's presence and even requested it. He did it to feel more confident and safe rather than to transfer the care responsibility to his family: "I would rather have my mother and my sister here in case anything happens" (I1; 14 June, 2011).

In addition, those who belong to his social network and represent the community where he is integrated are familiarized with his situation and do not exclude them from the social life or show feelings of repulse: "my friends are my cousins' friends. They even visited me at the hospital and I didn't even hide the bag" (I1; 16 June, 2011).

When talking about the activities carried out with his friends, such as playing football, the patient reported that "I can't play football for now, it will be more difficult. I can't be stumbling around as before" (I1; 15 June, 2011). On the contrary, when talking about his professional activity, the patient was concerned with the potential impact of his type of work on his new condition rather than the other way around, as in the case of playing football. The patient reported that: "I'm afraid of becoming ill with an infection from the wood dust at the sawmill" (I1; 13 June, 2011).

Throughout the 10-day hospitalization, the patient expressed his desire to be autonomous in caring for his stoma: "I want to live my life without depending on anyone to feel more at ease, I want to change the bag without needing any help" (I1; 17 June, 2011).

\section{Discussion}

The FAP diagnosis and the need for an ostomy are critical events that lead to the beginning of the transition process, namely a health/illness transition process.

The patient's awareness of the change seemed easier given his cousins' history of FAP but the fact that the person had never seen a sto$\mathrm{ma}$, the associated devices, or the process of caring for the stoma and the peristomal skin seem to give the idea of awareness as an unfinished state with multiple levels throughout the transition process. According to Meleis (2010), the transition process begins when the person is somewhat aware of the changes that are occurring or will occur. If the changes or their implications are denied because they are not consciously recognized, the person is not yet in the transition process.

The full awareness of change hardly occurs in the initial stage of transition because the person needs time to identify what has changed and only perceives this difference when faced with the change(s) in his/her daily life. Although the person experiences a transition process in the postoperative period, because he/she is already somehow aware of the change, change cannot be considered as finished because the confrontation with the difference and the associated difficulties will only occur when the person returns home.

The patient should have attended the preoperative stomal therapy consultation to have a greater awareness of the change. According to RNAO's guidelines on Ostomy Care and Management (RNAO, 2009), the nurse explains the type of ostomy that will be performed, marks the stoma site, and provides documentation about the surgery and the contact of other patients with an intestinal stoma (reference groups/role models).

Although the contact with the ileostomy bag in the preoperative phase can improve the person's level of awareness about the change and have a positive impact on his/her well-being, it can also have an adverse effect, representing a critical negative event in the transition process. El-Tawil and Nightingale (2013) found that a stoma bag can be challenge to the person's notion of identity. The visualization and use of the ostomy bag before surgery can lead a person to experience the new condition in advance, causing a conflict between his/her pre- and post-surgery identities.

According to the patient's account, the personal condition that facilitated his transition according was the meaning assigned to the surgery and the ileostomy. Surgery is seen as the cure for his problem and as a way to reduce his symptoms; ileostomy is seen as a temporary consequence of the surgery. This does not mean that the patient was satisfied with his diagnosis and the need for an ileostomy, but rather that he had positive expectations about the future resolution of his situation. This result is in line with the study of 
Smith, Spiers, Simpson, and Nicholls (2016), in which stoma surgery was found to have a positive impact on patients if it mitigates previous symptoms, thus improving their quality of life.

In view of the above, a transition is influenced by the internal and external conditions of the person who experiences it. These conditions cannot be considered, beforehand, as facilitating or inhibiting factors of the transition without being contextualized. The influence exerted by the intrinsic and extrinsic conditions of the person undergoing the transition process is rooted in its meaning, scope, and impact on the person's unique and unrepeatable context, rather than in the nature of the condition itself.

In the specific situation of this case study, the patient was confronted with the FAP diagnosis and the need for an ileostomy, as well as with the notion that, if the surgery was not performed, he would develop, sooner or later, colorectal cancer. However, the patient seemed to assign a positive meaning to the surgery and the ileostomy because he took his cousins' experience as a reference instead of his father's history. This evidence calls for a reflection on issues associated with the influence of personal conditions in the transition process, which depend on the person's individual characteristics (values, beliefs, and expectations) and the context (family, community, society, and country) where he/she is inserted.

Although the patient had never seen his cousins' bag, his proximity with the cousins gave him some knowledge to cope with his new condition. Therefore, the patient showed some interest in improving his knowledge about the disease and its implications, as well as in developing ileostomy self-care skills. The patient's level of commitment during the transition process is reflected in his evident readiness to learn and awareness of change.

Behaviors such as the lack of aversion to the stoma when seeing it for the first time should be understood as process indicators which, in this specific situation, provide data on the dimensions of feeling located/feeling situated. They also reveal that the individual uses problem-focused coping strategies, namely confrontation coping strategies.
Family support, as well as the social and cultural influence, are facilitating factors of this transition. To encourage the development of self-confidence, family and friends seem to serve as a support network that provides help, care, and attention which are essential for the individual to adapt to the emerging difficulties. Consequently, instead of hiding the bag, the person showed it without fear of rejection. These results are in line with the study of Smith et al. (2016), who reported that the relationship between ileostomy patients and their family and friends is often challenged by the new condition/status and that family and social support, when present, helps the person living with an ileostomy.

When talking about the activities carried out with friends, for example playing football, there is a clear perception of the difference. There is a consistency between the patient's reality and his expectations towards this reality. If patients are able to foresee future implications of the new condition in their lives, they are able to project themselves in the future as ileostomy patients.

With regard to meanings, attitudes, and cultural beliefs, this case study allows assessing the perception of the potential influence of professional activity in the ileostomy. The patient was concerned with the effect of the wood dust in his condition; however, he showed no concern about the influence of his new condition in his work, which may demonstrate a lack awareness about this aspect. In this regard, Brown and Randle (2005) suggest, in their study of reference in this area, that $15 \%$ of people living with a stoma experience changes in their professional life.

The domain of stoma self-care competence is a key criterion for the transition process to be considered as finished. To this end, the person needs to develop the following dimensions of the intestinal stoma self-care competence: knowledge, self-monitoring, interpretation, decision-making, execution, and negotiation and use of health resources (Silva, Cardoso, Gomes, Santos, \& Brito, 2016). In this specific situation, the person only developed the dimensions of knowledge, self-monitoring, and execution.

Taking into account that nursing interventions integrate the transition process, 
nurses can influence the transition process if they consider the individual's needs. In this context, patient's major need relate to the development of the ileostomy self-care competence, which would enable him to be autonomous in caring for the ileostomy, just as he would have liked it, through the development of new knowledge, skills, and attitudes. The nurse must consider the individual's potential to develop or improve his/her knowledge about the ileostomy and the skills to care for the stoma and the peristomal skin, in order to plan and prescribe interventions aimed at promoting and enhancing patients' autonomous and competent performance of ileostomy self-care.

Since the data from this study reflect the reality experienced by a single patient, the results cannot be generalized to all patients living with an ileostomy. Further nursing studies should be conducted to investigate the applicability of the transitions theory to concrete cases, so as to contribute toward the development of this theory and the development of new nursing knowledge.

\section{Conclusion}

The diagnosis of a genetic condition such as FAP, and the confrontation with the need for surgery and an ileostomy lead the person, who is aware of the changes involved, to experience a transition process. This experience, which is expected to culminate in a state of stability and adaptation to the new condition, is marked by a phase of vulnerability due to the challenges related to self-care.

This case study confirmed that the meanings assigned to the transition are influenced by the individual's intrinsic and external conditions. These conditions, which can be more or less significant, should always be contextualized.

Knowledge and skills proved to be conditions that facilitate transition because they had a positive influence on the key property of this process: awareness. There may be different levels of awareness but the initial transition phase is unlikely to be characterized by a complete awareness.

The meanings assigned to change and the new condition seem to interfere with the transition process and are associated with the patient's past experiences and cultural beliefs, values, and expectations. Therefore, when the individual faces a given situation, negative meanings inhibit transition, whereas positive meanings facilitate it. In the same way, the critical events that occur during the transition process may also be considered as positive or negative turning points, depending on the assigned meanings.

This case study allowed us to determine the scope and applicability of the transitions theory in this specific case, thus contributing toward a better understanding of the transition phenomenon, which was the purpose of this study. It also contributed to the development of the theory by showing that it can and should be applied in clinical practice.

The facts observed and the data collected in this case study, if considered separately, would have little meaning; however, when organized and integrated according to the transitions theory, they allow understanding the nature, conditions (facilitators and inhibitors), and response patterns of transitions.

Nurses play a key role in preparing patients to experience transitions, facilitating the process of development of the necessary skills to manage the change(s) resulting from the new condition.

Further research studies should be conducted to understand the nature, conditions, and response patterns that characterize individuals' experience of transition as a body of knowledge necessary to deliver nursing care to people experiencing transition processes.

\section{References}

Bowling, A. (2014). Research methods in health: Investigating health and health services ( $4^{\text {th }} \mathrm{ed}$.). New York, NY: McGraw Hill Education.

Brown, H. \& Randle, J. (2005). Living with a stoma: A review of the literature. Gastroenterology, 14(1), 74-81.

Burch, J. (2015). Examining stoma care guidance for nurses. Gastrointestinal Nursing, 3(6), 17-25.

Dalavi, S. B., Vedpalsingh, T. H., Bankar, S. S., Ahmed, M. H. S. \& Bhosale, D. N. (2015). Familial adenomatous polyposis (FAP): A case study and review of literature. Journal of Clinical and Diagnostic Research, 
9(3), 5-6. doi: 10.7860/JCDR/2015/11636.5696.

El-Tawil, A., \& Nightingale, P. (2013). Living with stoma: Long-term effects on patients' quality of life. Journal of Clinical \& Cellular Immunology. Advance online publication. Retrieval from http://dx.doi. org/10.4172/ 2155-9899.1000145

Kralik, D., Visentin, K., \& van Loon, A. (2006). Transition: A literature review. Journal of Advanced Nursing, 55(3), 320-329.

Meleis, A. I. (2015). Transitions theory. In M. C., Smith \& Parker, M. E., Parker (2015). Nursing theories \& nursing practice ( $4^{\text {th }}$ ed), pp. 361-380. Philadelphia, PA: F. A. Davis Company.

Meleis, A. (2010). Transitions theory: Middle-range and situation-specific theories in nursing research and practice. New York, NY: Springer.

Meleis, A., Sawyer, L. M., Im, E. O., Hilfinger Messias, D. K. \& Schumacher, K. (2000). Experiencing transitions: An emerging middle-range theory. Advances in Nursing Science, 23(1), 12-28.

Registered Nurses' Association of Ontario. (2009). Ostomy care and management: Clinical best practice guidelines. Toronto, Canada: Author.

Santos, V. (2015). A estomaterapia através dos tempos. In V. Santos \& I. Cesaretti (Eds.). Assistência em estomaterapia: Cuidando de pessoas com estomia (capi- tulo 1). São Paulo, Brasil: Atheneu.

Silva, C. R., Cardoso, T. M., Gomes, A. M., Santos, C. S., \& Brito, M. A. (2016). Construção do formulário de avaliação da competência de autocuidado na pessoa com ostomia de eliminação intestinal. Revista de Enfermagem Referência, 4(11), 21-30.

Smith, J. A., Spiers, J., Simpson, P., \& Nicholls, A. R. (2016). The psychological challenges of living with an ileostomy: An interpretative phenomenological analysis. Health Psychology, 36(12), 143-151. doi.10.1037/hea0000427

Stake, R. E. (1995). The art of case study research. Thousand Oaks, CA: Sage.

Vonk-Klaassen, S., de Vocht, H., den Ouden, M., Eddes, E., \& Schuurmans, M. J. (2016). Ostomy-related problems and their impact on quality of life of colorectal cancer ostomates: A systematic review. Quality of Life Research, 25(1), 125133. doi: 10.1007/s11136-015-1050-3

Youn-Jung, S., \& Mi-Ae, Y. (2015). Transitional care for older adults with chronic illnesses as a vulnerable population: Theoretical framework and future directions in nursing. Journal Korean Academy Nursing, 45(6), 919-927. doi: 10.4040/ jkan.2015.45.6.919 
